\title{
The Use of XML to Express a Historical Knowledge Base
}

\author{
Katsuko T. Nakahira, Masashi Matsui, Kazutoshi Abiko and Yoshiki Mikami \\ Nagaoka University of Technology \\ Japan
}

\section{Introduction}

Although the content currently available on the Web is easy for humans to read, it is not easy for computers. To address this, W3C is working on an activity, called the Semantic Web, in which items of content will be given semantic information so that they can be easily understood by computers. The goal of the activity is to convert the "document-based Web" intended for humans to a "data-based Web" that is understandable by computers(World Wide Web consortium, 2001). One effective application of the "data-based Web" to education may be the automatic collection, rearrangement and representation of written materials. For example, in the field of history, there are many records available on the Web, such as scientific papers and databases dealing with history or chronological tables. The descriptions in these records are not designed with the aim of allowing computers to understand or collect data automatically. If information about historical events could be collected and converted into a reusable format automatically, it would be possible to develop educational materials that allow history to be analyzed from a wider range of perspectives than is possible today.

There have been attempts to develop frameworks or languages to describe historical knowledge both in Japan and abroad. In Japan, the Technical Committee on Electrical Technology History of the Institute of Electrical Engineers of Japan, created a database on the history of electrical power system technology, and developed the Historical Space Modeling Language (HSML) and a GUI called Mandala for browsing historical information written in HSML(Matsumoto \& Yamada, 1998). Outside Japan, the Historical Event Markup and Linking (HEML) Project(Robertson, 2006) is developing its own XML schema designed for historical description, and a Web application that displays historical events in a variety of formats, such as chronological tables and maps. In the field of schedule management, iCalendar has been used as an event description format(Dawson \& Stenerson, 1998). This resembles the idea of historical description. Now that Web-based software is widely used, there have been attempts to write iCalendar in a manner compatible with Web technology, such as RDF Calendar, which writes iCalendar in Resource Description Framework (RDF), and microformats "hCalendar", which embeds items equivalent to iCalendar in XHTML data. 
(a)

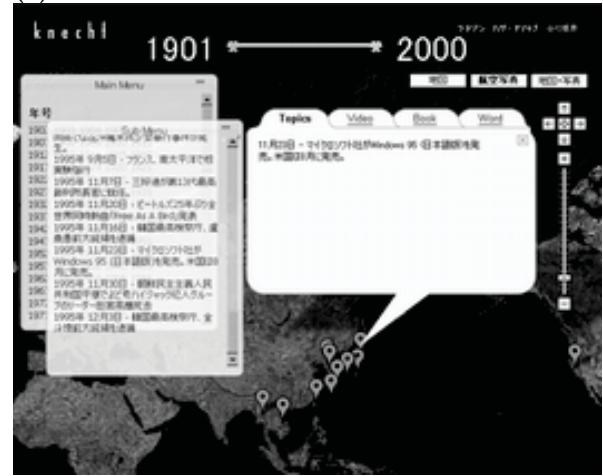

(b)

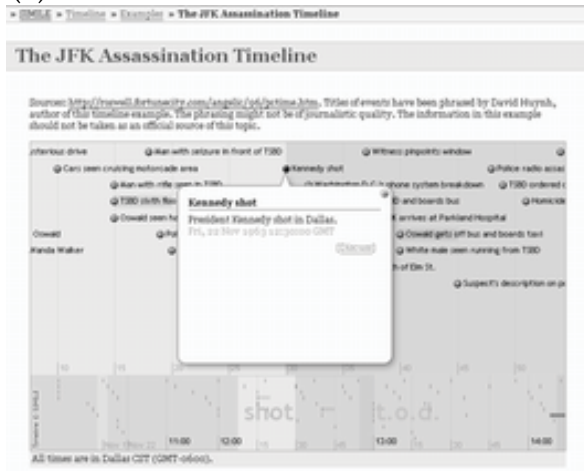

Fig. 1. (a) Knecht Chronicle (b) SIMILE Timeline

Research activities that focus on history include an attempt to liken items in a history study database to the Dublin Core ${ }^{1}$, which is a metadata framework for bibliographic information, and to map database items onto its vocabulary(Adachi \& Suzuki, 2006). In the field of historical studies, Yaegashi of the National Museum of Ethnology studied the handling of historical information in order to develop a multi-functional history study support system(Yaegashi, 1986; Yaegashi, 1989), and discussed how to process information in historical documents written in disparate formats. Akaishi et al. developed a mechanism for studying documents by accessing different types of information media in multiple databases built on different architectures (Akaishi et al., 1999; Itoh et al., 1999). All these studies pointed out the difficulties in developing an integrated tool because of the diversity of perspectives of researchers and learners of history, and difficulties in ensuring consistency in data because data is created using different architectures. To overcome these difficulties, Fujita et al. (Fujita et al., 1993) proposed a method of supporting the extraction of search information by converting historical text data into hypertext.

In parallel with the development of description formats, there have been attempts to represent historical knowledge in an intuitive, easy-to-understand manner. In Japan, Knecht has developed "Knecht Chronicle", a service that displays historical events on a map by combining different Web services, such as Google and Wikipedia (Figure 1(a)). ${ }^{2}$ Outside Japan, in a joint project called SIMILE, W3C, MIT Computer Science and Artificial Intelligence Laboratory, and MIT Libraries have developed, using AJAX, "Timeline" 3 , a tool to display a chronological table in a manner that allows intuitive operation using dragging with a mouse (Figure 1(b)). The "Cronus System" developed by the Editorial Engineering Laboratory ${ }^{4}$ allows us to see at a glance historical events that concurred in multiple fields. It can position historical events in a $3 \mathrm{D}$ space, a capability which enables us to understand the sequence of events and the relationship between different events. The Cronus System can also create historical data by itself, and create relationships between events by linking

\footnotetext{
${ }^{1}$ http:/ / dublincore.org/index.shtml (June, 2009)

${ }^{2}$ Knecht Chronicle, http://chronicle.knecht.jp/ (June, 2009)

${ }^{3}$ SIMILE. Timeline. http://www.simile-widgets.org/timeline/ (June, 2009)

${ }^{4}$ Cronos System, http://www.eel.co.jp/02_core/002_cronos/cronos.html (June, 2009)
} 


\begin{tabular}{|c|c|c|c|}
\hline & HSML & HEML & Timeline \\
\hline Classification & $\begin{array}{l}\text { Hierarchical classification } \\
\text { is possible by inheriting } \\
\text { classes }\end{array}$ & Possible to write this & None \\
\hline Time & Specifies year (month, day) & $\begin{array}{r}\text { Specifies year } \\
\text { (month, day) }\end{array}$ & $\begin{array}{l}\text { Year } \\
\text { (month,day, } \\
\text { time) }\end{array}$ \\
\hline Location & $\begin{array}{l}\text { No explicitly (however, } \\
\text { possible to write this as } \\
\text { part of an attribute) }\end{array}$ & Possible to write this & None \\
\hline Person involved & Possible to write developer & Possible to write this & None \\
\hline $\begin{array}{l}\text { Reference } \\
\text { information }\end{array}$ & Possible to write this & Possible to write this & $\begin{array}{l}\text { Possible to write } \\
\text { this }\end{array}$ \\
\hline Other attributes & $\begin{array}{l}\text { Possible to write many } \\
\text { attributes }\end{array}$ & None & Display icon \\
\hline
\end{tabular}

Table 1. Comparison of tags in HSML, HEML and Timeline

customized historical events using lines. Inoue et al.(Inoue et al., 2007) attempted at multidimensional representation of information by analyzing and visually presenting historical document data, with no metadata attached, according to the time space and geographical information, and discussed the possibility of such approaches. More recently, a study is in progress to use mobile phones to present historical information visually (Yamada et al., 2009).

As described, there have been a number of attempts to establish ways of representing knowledge of historical events, either by developing description languages or by making relationships between historical events visually understandable. However, there are few tools that can handle causal relationships. Among those mentioned above, only the set of HSML and Mandala by the Institute of Electrical Engineers of Japan can handle them. However, since HSML cannot be used without an HSML interpreter, it is not as readily usable as RDF, which is now widely used. The Cronus System can handle only those data created on the System.

To develop a system that can analyze the rich information resources available on the Web from multiple perspectives, as the Cronus System does, it is necessary to determine an underlying framework for the description of historical events. This paper aims to consider such a method of knowledge representation, focusing in particular on technology history, in which it is easy to find clear causal relationships.

\section{Description Frameworks}

\section{1 description methods}

In studying the framework for describing technology history, we first studied event (historical event) description tags. As models for such tags, we studied HSML, HEML, and Timeline, and compared their tag structures. HSML allows its tag structure to be extended to suit the specific application field. The comparison is shown in Table 1. HSML provides the highest expression capability, but its tag types are classified in too much detail for the 


\begin{tabular}{|l|l|}
\hline Case & Description \\
\hline \hline Agentive & Role of the person who causes a certain action \\
\hline Experience & Role of the person who experiences a psychological phenomenon \\
\hline Instrumental & $\begin{array}{l}\text { Role that is a direct cause of an event or that stimulates a reaction in } \\
\text { relation to a psychological phenomenon }\end{array}$ \\
\hline Objective & $\begin{array}{l}\text { Moving object or changing object. Or, role that expresses the content of } \\
\text { a psychological phenomenon, such as judgment or imagination }\end{array}$ \\
\hline Source & $\begin{array}{l}\text { The starting point from which the object moves, and the role that } \\
\text { expresses the original state or shape when the state or shape changes }\end{array}$ \\
\hline Goal & $\begin{array}{l}\text { The goal the object reaches, and the final state or result when the state } \\
\text { or shape changes }\end{array}$ \\
\hline Locative & Role of expressing the location where an event occurs \\
\hline Time & Role of expressing the time when an event occurs \\
\hline
\end{tabular}

Table 2. Fillmore's deep cases(Nagao, 1996)

description of general historical events. We decided that the information handled in HEML was sufficient for the description of items that appear in chronological tables. To check the expression capability of the tags and the ease of handling them, we developed a prototype chronological table using HEML for the description of historical events and Timeline for their visual presentation, and confirmed that the XML schemas of HEML are mutually interoperable.

We next studied description items. This paper uses deep cases of Fillmore's classical case grammar as our underlying framework for studying the items of description suitable for historical events. We compared existing description formats in terms of how well they correspond to the items derived from the deep cases. A deep case indicates the role an individual word plays vis-à-vis the verb. Any historical event can be associated at least with a subject and an action it takes. Therefore, we consider that the framework based on the concept of deep cases provides the widest range of description items regarding an event description. The eight cases given by Fillmore's deep case are shown in Table 2.

When the eight cases are applied to the description of historical events, they can be described as follows. The agentive case refers to the entity that caused an event. This entity may be an individual or an organization. The instrumental case corresponds to the cause of an event that occurred. The objective case applies to the object to which an event occurred, but its nature depends on the nature of the event. For example, when a new technology is being developed, the technology is the objective case. The location case corresponds to the place where an event occurred while the time case indicates the time when an event occurred. Since an event can be said to be expressed in direct discourse, the experiencer case does not exist. It is more difficult to interpret what the source case and the goal case represent. Unlike time or place, whether there are starting and goal points depends greatly on the nature of event (verb). Therefore, in this paper, we assume that no roles exist that correspond to the source or goal case for an event.

Consequently, we consider that a historical event may be defined by five elements: person, cause, object, location and time. 


\begin{tabular}{|c|c|c|c|c|c|}
\hline Deep case & Item name & HEML & iCalendar & Dublin Core & Timeline \\
\hline Agentive & Person & $\begin{array}{l}\text { Possible to } \\
\text { write name } \\
\text { and title of } \\
\text { the person }\end{array}$ & $\begin{array}{l}\text { Possible to } \\
\text { write name } \\
\text { and contact } \\
\text { point of the } \\
\text { host of the } \\
\text { event }\end{array}$ & $\begin{array}{l}\text { Possible to } \\
\text { write this }\end{array}$ & - \\
\hline Instrumental & Cause & - & - & - & - \\
\hline Time & Time & $\begin{array}{l}\text { Possible to } \\
\text { write starting } \\
\text { and ending } \\
\text { times }\end{array}$ & $\begin{array}{l}\text { Possible to } \\
\text { write starting } \\
\text { and ending } \\
\text { times }\end{array}$ & $\begin{array}{lr}\text { Possible } & \text { to } \\
\text { write } & \text { event } \\
\text { creation } & \text { time } \\
\text { and its bounds }\end{array}$ & $\begin{array}{lr}\text { Possible to } \\
\text { write } & \text { starting } \\
\text { and } & \text { ending } \\
\text { times } & \end{array}$ \\
\hline Locative & Location & $\begin{array}{l}\text { Possible to } \\
\text { write name } \\
\text { and the } \\
\text { latitude/long } \\
\text { itude of the } \\
\text { location }\end{array}$ & $\begin{array}{l}\text { Possible to } \\
\text { write name of } \\
\text { the location }\end{array}$ & $\begin{array}{l}\text { Possible to } \\
\text { write name } \\
\text { and the } \\
\text { latitude/longit } \\
\text { ude of the } \\
\text { location }\end{array}$ & - \\
\hline \multirow[t]{5}{*}{ Objective } & Object & - & - & $\begin{array}{l}\text { Possible to } \\
\text { write this }\end{array}$ & - \\
\hline & Event name & $\begin{array}{l}\text { Possible to } \\
\text { write this }\end{array}$ & $\begin{array}{l}\text { Possible to } \\
\text { write this }\end{array}$ & $\begin{array}{l}\text { Possible to } \\
\text { write this }\end{array}$ & $\begin{array}{l}\text { Possible to } \\
\text { write this }\end{array}$ \\
\hline & Description & & $\begin{array}{ll}\text { Possible } & \text { to } \\
\text { write this } & \end{array}$ & $\begin{array}{l}\text { Possible to } \\
\text { write this }\end{array}$ & $\begin{array}{ll}\text { Possible } & \text { to } \\
\text { write this } & \end{array}$ \\
\hline & $\begin{array}{l}\text { Reference } \\
\text { information }\end{array}$ & $\begin{array}{l}\text { Possible to } \\
\text { write this }\end{array}$ & $\begin{array}{l}\text { Possible to } \\
\text { write this }\end{array}$ & $\begin{array}{l}\text { Possible to } \\
\text { write this }\end{array}$ & $\begin{array}{l}\text { Possible to } \\
\text { write this }\end{array}$ \\
\hline & Other & $\begin{array}{l}\text { Supports } \\
\text { multiple } \\
\text { languages }\end{array}$ & $\begin{array}{l}\text { Possible to } \\
\text { write priority } \\
\text { and related } \\
\text { events }\end{array}$ & $\begin{array}{l}\text { Being based on } \\
\text { bibliographical } \\
\text { information, } \\
\text { there are items } \\
\text { on rights } \\
\text { holder, etc. }\end{array}$ & $\begin{array}{l}\text { Possible to } \\
\text { write } \\
\text { presentation- } \\
\text { related items, } \\
\text { such as color } \\
\text { of text } \\
\text { characters and } \\
\text { icon }\end{array}$ \\
\hline
\end{tabular}

Table 3. Presence/absence of Fillmore's deep case items in existing event description methods

\subsection{Presence/absence of items of deep cases in existing description methods}

To find candidates for event description items, we compared iCalendar, HEML, Timeline, and Dublin Core. The comparison results are shown in Table 3.

When it comes to individual items that can be identified and recorded, HEML provides means for making the most detailed description, such as the geographical information of latitude/longitude and the title of the person concerned. Timeline is simpler than other description methods because it is specifically designed for the description of a chronological table. In Timeline, all the elements considered in the Section 2.1 are written in the "explanation" part.

All the description methods allow links to reference information to be written. "Explanation" does not fit any deep cases. Since "explanation" represents an event itself, it embraces all deep cases. Therefore, "Explanation" should not be included as one of the 
structured historical event items. Since the vast information of knowledge relating to a historical event should be described using a hierarchical structure, it is realistic to describe such details in lower layers (references indicated by reference information).

Although none of the description methods other than Dublin Core have items for describing the subject in question, their event name takes the form of "subject + verb" in most cases. Therefore, it can be considered that the event name includes the information about the subject.

Table 3 shows that Dublin Core has the largest number of description items. Since it was originally developed for bibliographic information, it includes some parts that are inappropriate for the description of an event. For example, we have assumed that the creator item can include the description of persons, but if we take "the Battle at Sekigahara" as an example of a historical event, who is the creator of the Battle? It is possible to assume that the time of the event fits either the expiration date (date) or the temporal coverage (coverage), but which of these is more appropriate? Dublin Core defines 12 elements, called DCTYPE, as a vocabulary of type elements that express resource types. One of them is "Event". When we attempt to apply this to an actual event, we encounter a variety of interpretation problems. Sometimes, it is necessary to extend the definitions. For these reasons, a detailed study is needed before applying Dublin Core to the description of an event.

All the description methods have adequate expression capability to write basic information about an event. However, none of them allows the description of causes. Since when describing history we consider causal relationships, it is necessary to develop a new description method that allows the description of causes.

\subsection{Relationships between events}

We investigated how to describe the relationships between events. The description of the history of technology would require not only a description of the attributes of each event but also a description of the relationships between events, such as causal relationships. Therefore, we investigated the probability of being able to find a description about the relationships between each technology and the conditions surrounding it or the social background to it in actual literature about the history of technology. This probability may

\begin{tabular}{|c|c|c|}
\hline \multirow[b]{2}{*}{ Item } & \multicolumn{2}{|c|}{ Number of sentences } \\
\hline & $\begin{array}{l}\text { (1) Report by the } \\
\text { Institute of Electrical } \\
\text { Engineers of Japan }\end{array}$ & $\begin{array}{l}\text { (2) A Short History of } \\
\text { Twentieth Century } \\
\text { Technology }\end{array}$ \\
\hline Technology & $50(61 \%)$ & $31(39 \%)$ \\
\hline From technology to technologh & $1(1 \%)$ & $7(9 \%)$ \\
\hline From technology to environment & $3(4 \%)$ & $7(9 \%)$ \\
\hline Environment & $11(13 \%)$ & $20(25 \%)$ \\
\hline From environment to environment & $0(0 \%)$ & $2(3 \%)$ \\
\hline From environment to technologh & $4(5 \%)$ & $9(11 \%)$ \\
\hline Others & $13(16 \%)$ & $3(4 \%)$ \\
\hline Total & 82 & 79 \\
\hline
\end{tabular}

Table 4. Distribution of description content in publications on the history of technology 
vary depending on the authors or the field of each publication. We selected the report (Ishii \& Arai, 1999) by the Technical Committee on the History of Nationalization of Electrical Technology of the Institute of Electrical Engineers of Japan, which is considered to focus on technological description. We also selected the Section of "Technology at Home" in "A Short Story of Twentieth Century Technology" by Trevor I. Williams as an example of literature with a heavy weight given to social background (Williams, 1987).

The result is shown in Table 4 . While about $60 \%$ of sentences in the report by the Institute of Electrical Engineers of Japan concentrated on technology itself, this percentage is about $40 \%$ in the case of "A Short History of Twentieth Century Technology." In both publications, the description about the socio-economic environment accounted for $15-20 \%$, which implies that the framework for the description of events should take non-technical events into consideration as well. The descriptions about the relationships between events amounted to $10-30 \%$, which suggests that it is necessary to carefully consider inter-event relationships regardless of the nature of the publication. Therefore, it is important to study the framework for the description of inter-event relationships. HSML allows event attributes to describe inter-event relations, and thus has tags that indicate preceding events or subsequent events. In addition, HSML provides a "used_by" tag and a "developed_by" tag, and allows users to define new tags to describe relationships as necessary. It thus has an extremely high description capability. However, to use these tags, it is necessary to introduce non-event classes, such as person or organization, which increases the complexity of the entire description system.

\section{3. description method}

\subsection{Selection of microformat vocabulary}

We use RDF, which is now widely used on the Web, as the data format for historical events. However, while RDF is easy for computers to read, it is not easy for humans. Therefore, we mark up attributes, etc. in an HTML document, extract data that is easy to read for computers from the HTML document, and output this data in RDF. We use microformats as the framework for writing metadata inside an item of content. Microformats extract metadata from a document by giving names to attribute values in XHTML. Attribute values provided in the XHTML grammar are used. An advantage of this approach is that it can be applied to existing items of content with almost no requirements for modifying their structure. Since we are considering the application of our method to existing historical event descriptions, we have chosen to use microformats for their above-mentioned advantage. One specification of microformats is hCalendar, in which iCalendar is implemented as microformats. However, hCalendar does not allow the latitude/longitude information or causes to be recorded. Therefore, we have newly defined the vocabulary of microformats.

In addition, we have developed a method, based on XSLT, of extracting metadata of the defined microformats and converting it to RDF. XSLT is a conversion language that converts one XML document into another XML document. We associate an XSLT file with an item of content by specifying it in a link element in XHTML. The agent can automatically extract 


\begin{tabular}{|c|c|c|c|c|c|c|c|}
\hline Classification & Case & Element & Attribute & Value & Item & Location & Data type \\
\hline Event & Objective & $\begin{array}{l}\text { Not } \\
\text { specified }\end{array}$ & class & event & $\begin{array}{l}\text { event } \\
\text { name }\end{array}$ & $\begin{array}{l}\text { title } \\
\text { attribute }\end{array}$ & $\begin{array}{l}\text { character } \\
\text { string }\end{array}$ \\
\hline \multirow{4}{*}{ Time } & \multirow{4}{*}{ Time } & \multirow{2}{*}{$\begin{array}{l}\text { Not } \\
\text { specified }\end{array}$} & \multirow{2}{*}{ class } & \multirow{2}{*}{ start_data } & $\begin{array}{l}\text { Sharing } \\
\text { date name }\end{array}$ & $\begin{array}{l}\text { within } \\
\text { element }\end{array}$ & $\begin{array}{l}\text { character } \\
\text { string }\end{array}$ \\
\hline & & & & & $\begin{array}{l}\text { starting } \\
\text { date name }\end{array}$ & $\begin{array}{l}\text { title } \\
\text { attribute }\end{array}$ & date \\
\hline & & \multirow{2}{*}{$\begin{array}{l}\text { Not } \\
\text { specified }\end{array}$} & \multirow{2}{*}{ class } & \multirow{2}{*}{ end_date } & $\begin{array}{l}\text { ending } \\
\text { date }\end{array}$ & $\begin{array}{l}\text { within } \\
\text { element }\end{array}$ & $\begin{array}{l}\text { character } \\
\text { string }\end{array}$ \\
\hline & & & & & $\begin{array}{l}\text { ending } \\
\text { date }\end{array}$ & $\begin{array}{l}\text { title } \\
\text { attribute }\end{array}$ & date \\
\hline \multirow{2}{*}{ Location } & \multirow{2}{*}{ Location } & \multirow{2}{*}{ Free } & \multirow{2}{*}{ class } & \multirow{2}{*}{ location } & $\begin{array}{l}\text { location } \\
\text { name }\end{array}$ & $\begin{array}{l}\text { within } \\
\text { element }\end{array}$ & $\begin{array}{l}\text { character } \\
\text { string }\end{array}$ \\
\hline & & & & & lat/long & $\begin{array}{l}\text { title } \\
\text { attribute }\end{array}$ & numerical \\
\hline \multirow{2}{*}{ Participant } & \multirow{2}{*}{ Agentive } & \multirow{2}{*}{ a } & \multirow{2}{*}{ rel } & \multirow{2}{*}{ participant } & $\begin{array}{l}\text { participant's } \\
\text { name }\end{array}$ & $\begin{array}{l}\text { title } \\
\text { attribute }\end{array}$ & $\begin{array}{l}\text { character } \\
\text { string }\end{array}$ \\
\hline & & & & & $\begin{array}{l}\text { participant's } \\
\text { URL }\end{array}$ & $\begin{array}{l}\text { href } \\
\text { attribute }\end{array}$ & URL \\
\hline \multirow{2}{*}{ Evidence } & \multirow{2}{*}{-} & \multirow{2}{*}{$\mathrm{a}$} & \multirow{2}{*}{ rel } & \multirow{2}{*}{ evidence } & $\begin{array}{l}\text { evidence } \\
\text { name }\end{array}$ & $\begin{array}{l}\text { title } \\
\text { attribute }\end{array}$ & $\begin{array}{l}\text { character } \\
\text { string }\end{array}$ \\
\hline & & & & & $\begin{array}{l}\text { evidence } \\
\text { URL }\end{array}$ & $\begin{array}{l}\text { href } \\
\text { attribute }\end{array}$ & URL \\
\hline \multirow{2}{*}{ Cause } & \multirow{2}{*}{ Instrumental } & \multirow{2}{*}{ a } & \multirow{2}{*}{ rel } & \multirow{2}{*}{ cause } & cause name & $\begin{array}{l}\text { title } \\
\text { attribute }\end{array}$ & $\begin{array}{l}\text { character } \\
\text { string }\end{array}$ \\
\hline & & & & & cause URL & $\begin{array}{l}\text { href } \\
\text { attribute }\end{array}$ & URL \\
\hline
\end{tabular}

Table 5. Proposed "microformat" vocabulary set

metadata using this XSLT file. The mechanism in which a computer associates an XSLT file with a document to extract metadata is called GRDDL (Gleaning Resource Descriptions from Dialects of Languages). As exemplified by W3C's establishment of the GRDDL Working Group 5 , further efforts are expected to be taken to develop specifications, technologies and application examples of GRDDL. Against this background, we have defined the microformat vocabulary shown in Table 5.

An event is represented by one element. This element has the "event" value in its class attribute. The event name is written in the title attribute of that element. Any further information about the event is written inside this element.

The time when an event occurred is written using the content of the element that has the "start_date" value in its class attribute, and using the value of the title attribute. Examples of the content of this element are "At the beginning of the 19th century" and "At 5:56 p.m. on October 23, 2004." The content can be a numeric value or a character string. The content of the title attribute is of the date format. Specifically, it is of either the dateTime format, date format, gYearMonth format, or gYear format, all defined in XML Schema. If an event has a certain duration, the end of the duration is expressed by an element that has the "end_date" value in its class attribute. The manner in which the content is written in this case is the same as that of writing the starting time of the event.

The location where an event occurred is expressed by the content of an element that has the "location" value in its class attribute and using the title attribute of that element. The content

\footnotetext{
${ }^{5}$ http://www.w3.org/2001/sw/grddl-wg/ (available, June 2009).
} 


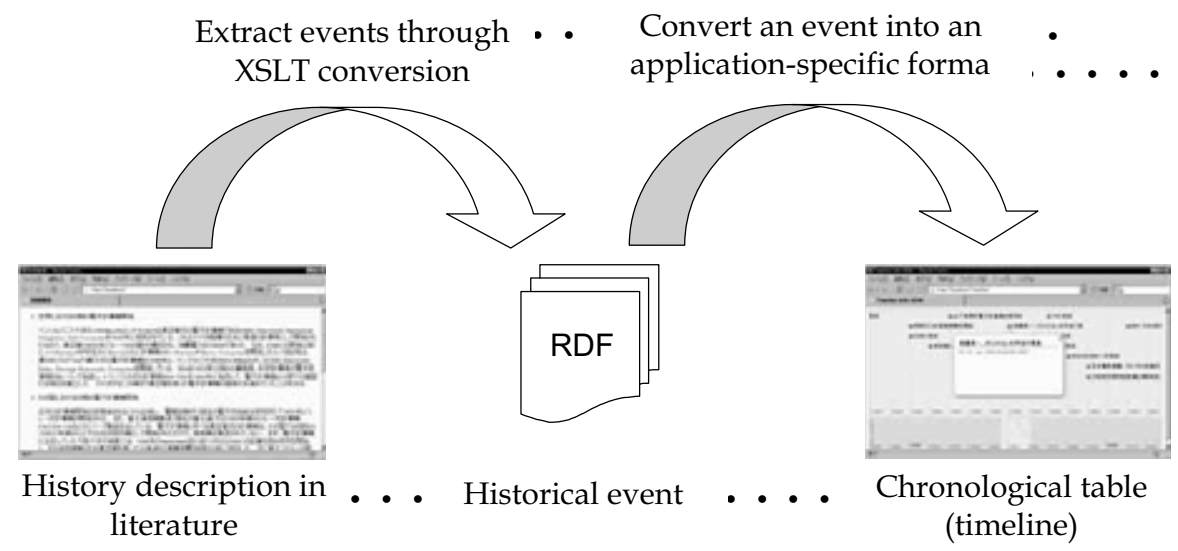

Fig. 2. Sequence of processing in the prototype

of the element indicates the location name. The latitude/longitude information is written in the title attribute in the form of "latitude, longitude", using a comma as the delimiter.

Persons, evidences and causes are written using an "a" element. Defined values of these are put in the rel attribute of the element. The name is written in the title attribute, and the URL is written in the href attribute of the element. There may not be appropriate URLs for the persons and evidences(source of information) involved in an event. In such a case, these are substituted for by putting the same value as that in the rel attribute in the class attribute of an arbitrary element. There may be many evidence that are contained in literature and thus cannot be expressed by URLs. This issue requires further study. As far as the subject of an event is concerned, we assume that it is included in the "subject + verb" of the event name, rather than newly defining a separate item

\subsection{Evaluation of the compatibility of the microformat vocabulary}

To evaluate the compatibility of the microformat vocabulary, we marked up documents on technology history using the microformat vocabulary shown in Table 5, and showed the marked-up events on the timeline of SIMILE. We used two reports from the Institute of Electrical Engineers of Japan: "Early development of electronic computers in the world" and "Early development of electronic computers in Japan." The general processing sequence of this experiment is shown in Figure 2. First, each report was marked up using the defined vocabulary. Events were extracted from each report using the XSLT associated with the report, and the RDFs that describe the events were obtained. These were then converted into the data format of the particular application (SIMILE Timeline in this experiment) and the events were shown.

Data in Timeline is of XML format and uses its own unique vocabulary. If we created an XSLT that directly converts the microformat format into the Timeline format, it would be possible to create Timeline data from the documents. However, we chose to first convert the microformat format into RDF, and then convert from RDF into the Timeline format. This was because we did not focus on a specific representation format but wanted to be able to handle a variety of representation formats. The result of this experiment confirmed that the extracted events can be mapped using a variety of timeline production tools. 


\section{Input Support Tool}

Considering that the above-mentioned selection of the vocabulary enables history to be described in a unified format, we proceeded to develop a tool that supports the input of educational materials on history. Specifically, this tool mainly supports attaching markup tags to input text. An overview of the tool is shown in Figure 3(a). First, the user obtains paper documents on history written in a natural language, or retrieves history document files from the Web. Next, he or she inputs the obtained documents using the input support tool, and then, aided by the input support functions of the tool, edits data based on the framework for describing historical events. The editing basically consists in identifying keywords by using defined tags. When the input of the historical events of a document has been completed, it is saved as an XML document file. Finally, the XML document is converted into RDF and registered in the DB.

The editor was implemented by combining Word Press, which is a PHP CMS, and OpenWYSIWYG, which is an open source editor. The following functions were implemented in this tool:

A) Consistent expression of person's name: When a person's name is used repeatedly in natural text, it is often omitted, or replaced with a pronoun, etc, to make reading and writing the text easier. This omission makes it difficult for computers to comprehend the text. If data is registered with the first or last name omitted, computers cannot recognize whether the persons involved are the same person or different persons. Since this can hamper sharing of data, we added a function to complement a person's name by presenting the user's input history and thereby ensuring consistency in expression.

B) Consistent expression of location's name: Historical documents, whether written in the past or recently, include the names of locations where historical events took place. Such location names may remain the same as in the past or may have changed over time. If the location name has changed, a single location may be registered as several different locations in the database. Therefore, we added a function to allow the latitude/longitude information to be input along with the location name, by referring to geographical information.

C) Consistent expression of years: A variety of calendar systems have been in use in the past and today. To describe a historical event, it is necessary to use a unique standard calendar system. We have adopted the Christian years as the standard years. However, even the Christian years have two versions: the Julian calendar and the Gregorian calendar. Besides, the year when the Christian years were adopted varied from country to country. Since our main focus was on implementing the tool, we closed our eyes to small differences. We thus developed a function that automatically converts non-standard calendar years to the Christian years.

Considering the above, we implemented the data flow shown in Figure 3(b). The input support functions were implemented using Ajax, which is a client-side technology, and PHP, which is a server-side technology. The editor (OpenWYSIWYG) of the prototype served as the basis for the tool. Since it is written in JavaScript, it is highly compatible with Ajax. HTML_AJAX was used for the interworking between JavaScript and PHP. HTML_AJAX is a PHP PEAR package. One of its advantages is that a class existing in the PHP server can be 
(a)

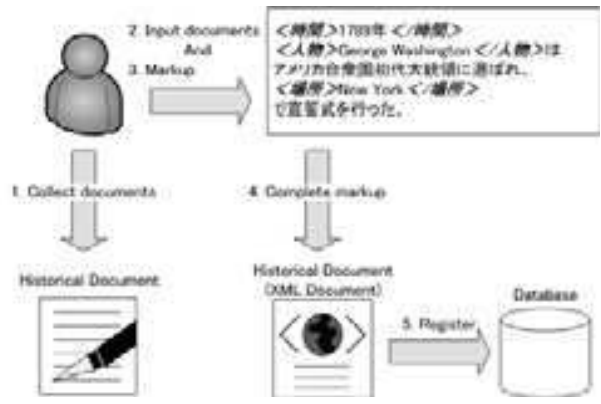

(b)

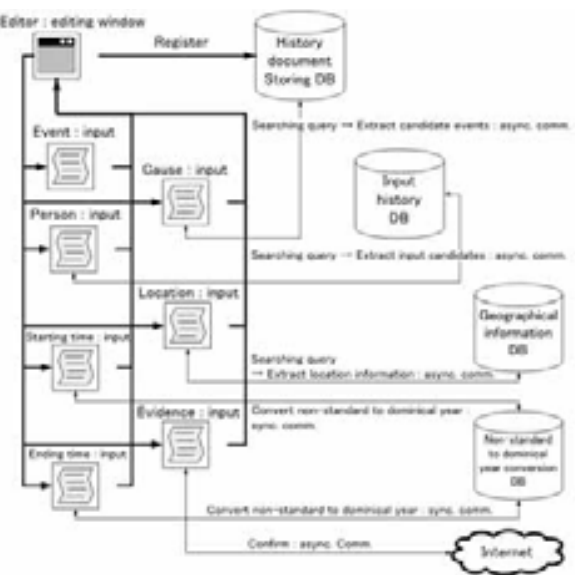

Fig. 3. (a) outline for Input/Output system, (b) Operation sequence of the input support tool

(a)

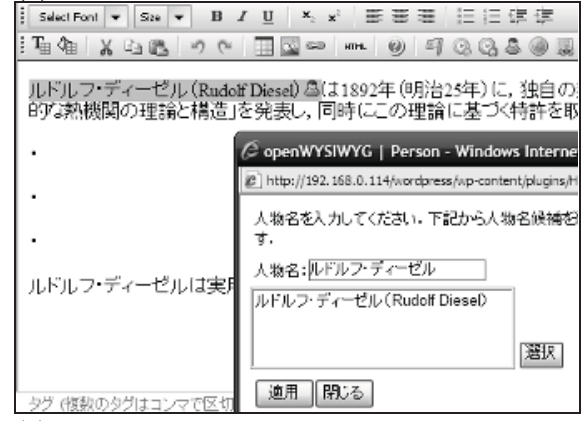

(c)

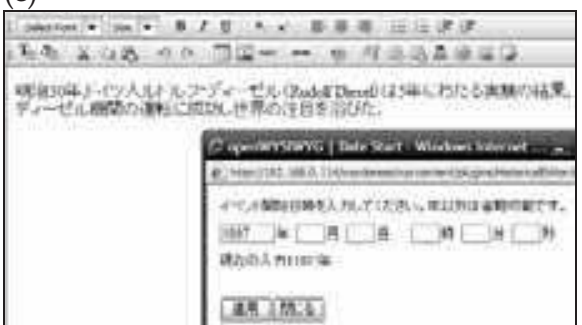

(b)

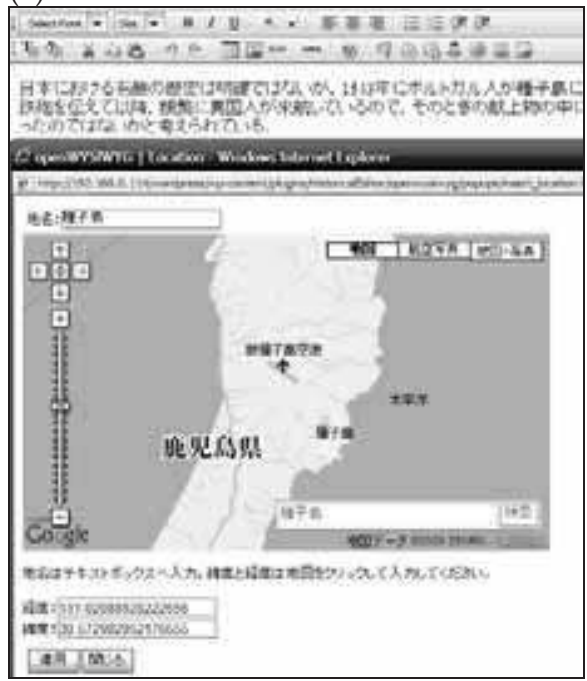

Fig. 4. Example of executing the (a)personal name complementing function, (b) location name complementing function, (c) year data conversion function 


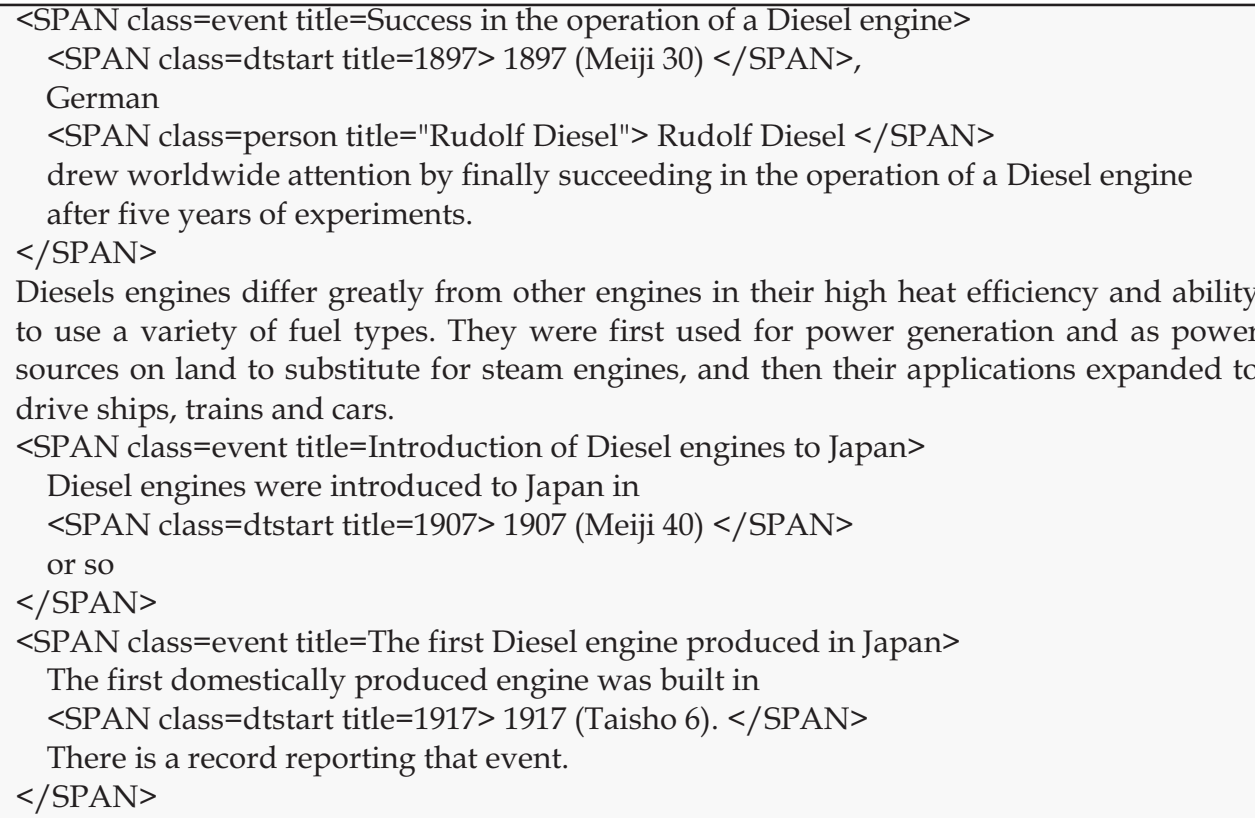

Fig. 5. Example of editing using the input support tool

executed from the client. This capability was used to implement the process of sending data from the server to the client, the issuing of queries to the input history database and the calendar system conversion database, and the processing of the obtained data. The Google Maps API service was used in the geographical information database to support the input of geographical information.

The windows of the implemented functions are shown in Fig. 4(a)-(c). We used two reports on research on systematizing technologies (Sato, 2008; Nakasone, 2007) as historical data. Figure 4(a) shows an example of executing the personal name complementing function. "Rudolf Diesel" is marked up as a personal name. Once this is done, when the user tries to mark up "Rudolf Diesel" again, the personal name complementing function provides a candidate from the input history. When the user executes markup by selecting the provided candidate, no apparent change occurs in the passage but actually "Rudolf Diesel" has been registered as XHTML metadata. Figure 4(b) shows an example of executing the location name complementing function. When the user tries to mark up the location name "Tanegashima Island", the location name complementing function presents a map of "Tanegashima Island" using Google Maps. When the user clicks a point in the map, the latitude and longitude data are retrieved, and registered in the relevant metadata along with the location name. Figure 4(c) shows an example of executing the year data conversion function. When the user tries to mark up "Meiji Year 30 (according to the Japanese calendar)", the year data conversion function converts the Japanese calendar year to a dominical year, which is then registered in the relevant metadata.

The above-mentioned information was input to the input support tool. Text data that had been input using the markup function available in a GUI environment was marked up 
appropriately, and the data was saved as text with metadata attached as shown in Figure 5. The saved text data can be reused using a variety of tools.

\section{Conclusions}

To create a framework for describing historical events, we have compared and evaluated existing history description languages based on the deep cases of Fillmore's case grammar, and developed a unique description framework by adding items that are lacking in the existing languages. We have also created a microformat vocabulary set suitable for this framework. In addition, we have used an existing editor to mark up technology history to examine the usability of the editor. To further enhance the usability of the editor, we have implemented input support functions, such as supplementing persons' names, supplementing location names, and converting calendar systems. In particular, we have adopted Christian years as the standard calendar years but ignored minor differences between the Julian and Gregorian calendars in the implementation in order to allow early verification of the usability of the input support functions. When the editor is to be applied for commercial purposes, the differences between the Julian and Gregorian calendars will not be negligible. We plan to solve this problems at an early opportunity. Another issue for future study is the development of a tool that presents, in an intuitive manner, events marked up using the vocabulary we have defined.

\section{References}

F. Adachi; T. Suzuki(2006). A Study on Mapping of Historical Research Database to Dublin Core Metadata, SIG Technical Reports of Information Processing Society of Japan, Vol. 2006, No. 112, 47-54, ISSN 0919-6072.

M. Akaishi; Y. Okada; H. Nakatani; Y. Itoh; \& S. Tamura(1999). The Historical Data Management and visualization system for History Research Supports, Journal of Information Processing Society of Japan, Vol. 40, No. 3, pp. 831-838, ISSN 0387-5806.

F. Dawson; D. Stenerson(1998). RFC 2445 - Internet Calendaring and Scheduling Core Object Specification (iCalendar) . [Online]. Available: http://tools.ietf.org/html/rfc2445 (June, 2009)

S. Fujita; K. Sugawara; M. Iyoda; \& Junki Yaegashi(1993). Application of Reverse Engineering to Design of Full-text Database for Supporting Historical Research, SIG Technical Reports of Information Processing Society of Japan, Vol. 1993, No. 98, 57-64, ISSN 0919-6072.

K. Inoue; S. Sasaki; \& Y. Kiyoki(2007). A Visualization System for Realizing Multiple Viewsfor Historical Documents, SIG Technical Reports of Information Processing Society of Japan, Vol. 54, 321-326, ISSN 0919-6072.

A. Ishii \& F. Arai(1999). Technology Creation, Asakura Shobo, ISBN 978-4254105292, Tokyo.

Y. Itoh; T. Konishi; T. Miura; D. Akatsuka; S. Tamura; K. Abe; M. Akaishi; \& H. Nakatani(1999). Extraction and Classification of Historical Documents and Overlook of Classification Results for Historical Research Supports, Journal of Information Processing Society of Japan, Vol. 40, No. 3, 821-830, ISSN 0387-5806.

Y. Matsumoto \& A. Yamada(1998). An association-based management of reusable software components, Annals of Software Engineering, Vol, 5 , 317-347, ISSN:1022-7091. 
M. Nagao(1996). Natural language processing, Iwanami Shoten Publishers, ISBN 9784000103558.

Y. Nakasone(2007). Research on Systematizing the Technological Development of Soap and Synthetic Detergents, National Science Museum: Report on Researches on Systematizing Technologies, Vol. 9, 1--58.

B. G. Robertson(2006). Visualizing An Historical Semantic Web with HEML. the Proceedings of the 15th International conference on World Wide Web, 1051-1052, ISBN:1-59593-323-9.

K. Sato(2008). Research on Systematizing the Technological Development of 4-cycle Diesel Engine, National Science Museum: Report on Researches on Systematizing Technologies, Vol. 12, 1--81.

J. Yaegashi(1986). Some Problems of the Data in Experimentation, SIG Technical Reports of Information Processing Society of Japan, Vol. 1986, No. 50, 1--8, ISSN 0919-6072.

J. Yaegashi(1989). Some Problems of Multifunctional system and data Aiding for Historical Studies, SIG Technical Reports of Information Processing Society of Japan, Vol. 1989, No. 85, 1-8, ISSN 0919-6072.

K. Yamada; H. Tarumi; T. Daikou; F. Kusunoki; S. Inagaki; M. Takenaka; T. Hayashi; \& M. Yano(2009). Development and Evaluation of a Mobile Learning System to Visit a Virtual Past World, Journal of Information Processing Society of Japan, Vol. 50, No.1, 372-382, ISSN 0387-5806.

T. I Williams(1987). A Short History of Twentieth Century Technology, Second Volume, Chikuma Shobo, ISBN 978-4480860194

World Wide Web Consortium(2001). W3C Semantic Web Activity. [Online]. Available: http://www.w3.org/2001/sw/ (June, 2009) 


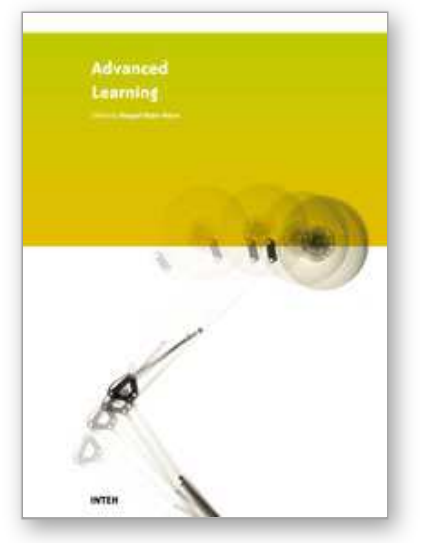

\author{
Advanced Learning \\ Edited by Raquel Hijn-Neira
}

ISBN 978-953-307-010-0

Hard cover, 444 pages

Publisher InTech

Published online 01, October, 2009

Published in print edition October, 2009

The education industry has obviously been influenced by the Internet revolution. Teaching and learning methods have changed significantly since the coming of the Web and it is very likely they will keep evolving many years to come thanks to it. A good example of this changing reality is the spectacular development of eLearning. In a more particular way, the Web 2.0 has offered to the teaching industry a set of tools and practices that are modifying the learning systems and knowledge transmission methods. Teachers and students can use these tools in a variety of ways aimed to the general purpose of promoting collaborative work. The editor would like to thank the authors, who have committed so much effort to the publication of this work. She is sure that this volume will certainly be of great help for students, teachers and researchers. This was, at least, the main aim of the authors.

\title{
How to reference
}

In order to correctly reference this scholarly work, feel free to copy and paste the following:

Katsuko T. Nakahira, Masashi Matsui, Kazutoshi Abiko and Yoshiki Mikami (2009). The Use of XML to Express a Historical Knowledge Base, Advanced Learning, Raquel Hijn-Neira (Ed.), ISBN: 978-953-307-010-0, InTech, Available from: http://www.intechopen.com/books/advanced-learning/the-use-of-xml-to-express-a-historicalknowledge-base

\section{INTECH}

open science | open minds

\section{InTech Europe}

University Campus STeP Ri

Slavka Krautzeka 83/A

51000 Rijeka, Croatia

Phone: +385 (51) 770447

Fax: +385 (51) 686166

www.intechopen.com

\section{InTech China}

Unit 405, Office Block, Hotel Equatorial Shanghai

No.65, Yan An Road (West), Shanghai, 200040, China

中国上海市延安西路65号上海国际贵都大饭店办公楼405单元

Phone: +86-21-62489820

Fax: $+86-21-62489821$ 
(C) 2009 The Author(s). Licensee IntechOpen. This chapter is distributed under the terms of the Creative Commons Attribution-NonCommercial-ShareAlike-3.0 License, which permits use, distribution and reproduction for non-commercial purposes, provided the original is properly cited and derivative works building on this content are distributed under the same license. 